\title{
THE EFFECT OF CHANGES IN BODY SODIUM ON EXTRACELLULAR FLUID VOLUME AND ALDOSTERONE AND SODIUM EXCRETION BY NORMAL AND EDEMATOUS MEN ${ }^{1}$
}

\author{
BY LEROY E. DUNCAN, JR., GRANT W. LIDDLE, AND FREDERIC C. BARTTER \\ WITH THE ASSISTANCE OF KATHERIN BUCK \\ (From the Clinic of General Medicine and Experimental Therapeutics, National Heart Insti- \\ tute, National Institutes of Health, Public Health Service, U. S. Department of Health, \\ Education, and Welfare, Bethesda, Md.)
}

(Submitted for publication April 6, 1956; accepted August 2, 1956)

The presence of a sodium-retaining hormone, aldosterone, in the adrenal gland and adrenal venous blood (1-4), the increased urinary excretion of aldosterone during sodium depletion $(5,6)$ and the inability of men and animals with adrenal insufficiency to conserve sodium support the concept that the process by which the sodium content and thus the extracellular fluid (ECF) volume of the body are regulated includes adrenocortical control of sodium excretion by aldosterone secretion (7).

That aldosterone is involved in the formation of edema is indicated by an increased urinary output of this hormone by patients with edema caused by heart failure, portal cirrhosis or nephrosis (8-13).

The present work further defines the role of aldosterone in the control of ECF volume of normal men and in the formation of edema by patients with heart failure or portal cirrhosis.

\section{METHODS}

The patients lived on a metabolic ward during the studies. Constant diets were prepared from uniform lots of food. The patients were weighed each morning after voiding and before breakfast. Blood samples were drawn 3 times a week before breakfast. Total collections of urine and feces were made. Urine was kept at $5^{\circ}$ C. during and following collection. Sodium and potassium in diets, urine, feces and sera, and cation exchange resin in feces were determined as previously described (14). Uptake of sodium by resin was calculated on the assumption that there were $2 \mathrm{mEq}$. of sodium per day uncombined with resin in the stool (14).

Uptake of sodium in per cent $=$

$$
\frac{\text { mEq. fecal sodium/day }-2}{\mathrm{mEq} \text {. fecal resin/day }} \times 100 \text {. }
$$

1 Parts of this work have been reported briefly in the discussion of the paper of Dr. John A. Luetscher, Jr. at the 1955 Laurentian Hormone Conference and in abstract form (Circulation, 1955, 12, 697).
Sodium uptake is thus the percentage of the total exchange capacity of the resin occupied by sodium. The uptake of potassium by resin was calculated in the same fashion on the assumption that there were $10 \mathrm{mEq}$. of potassium per day uncombined with resin in the stool. The results are essentially the same if it is assumed that all of the sodium and potassium in the stool is combined with resin.

Urinary extracts of aldosterone were prepared by the following procedure within three days of the collection of urine. The urine was acidified to $\mathrm{pH} 1$ with $\mathrm{HCl}$ and divided into $1500 \mathrm{ml}$. batches. Water was added if necessary to achieve the proper volume. Each batch of urine was then placed in a glass tube $120 \mathrm{~cm}$. high by $4.3 \mathrm{~cm}$. in diameter. Urine was pumped from the bottom of this tube to the bottom of another tube $120 \mathrm{~cm}$. high by $2.5 \mathrm{~cm}$. in diameter. It ascended in droplets at the rate of $10 \mathrm{ml}$. per minute through $350 \mathrm{ml}$. of dichloromethane to the top of the tube whence it was returned to the top of the first tube. This extraction was continued for 22 hours. The dichloromethane had been previously purified by passage through a column of silica gel. Following the extraction the dichloromethane was washed twice with 0.1 its volume of $0.1 \mathrm{~N}$ sodium carbonate and twice with 0.1 its volume of water. The washings were backwashed with their volume of dichloromethane. The dichloromethane was then evaporated to dryness by passing nitrogen through it under reduced pressure at room temperature. The residue was dissolved in ethanol and stored at $-7^{\circ}$ C. until it was assayed in dogs for aldosterone (15). Urinary 17-hydroxycorticoids were determined in several patients by a modification of the method of Silber and Porter (16).

Venous pressure was measured by connecting a manometer directly to a needle inserted in an antecubital vein. With the patient reclining the venous pressure was recorded as the height of the fluid above a plane halfway between the uppermost portion of the sternum and the back of the patient.

\section{PROCEDURE AND RESULTS}

Dietary sodium for the different subjects varied from 6 to $12 \mathrm{mEq}$. per day. Dietary potassium was supplemented by potassium on cation exchange resin and in some cases by potassium salts. 


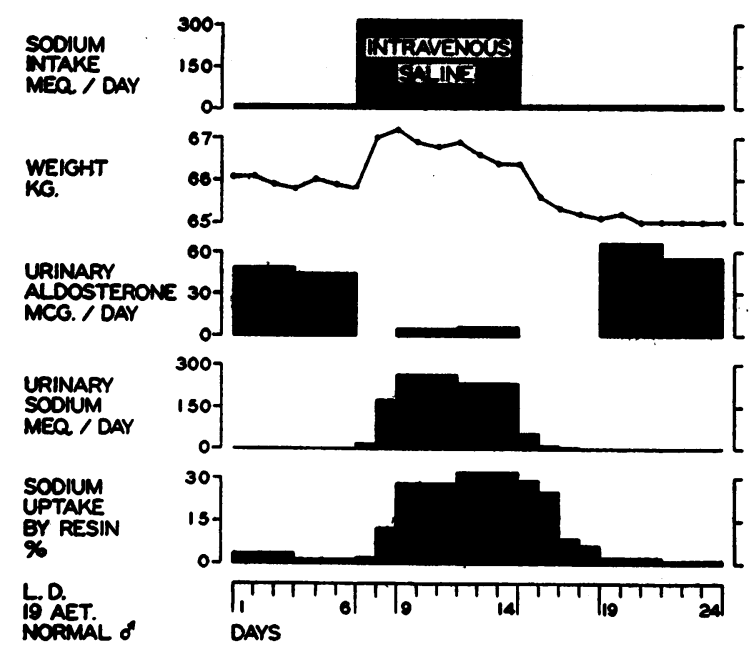

Fig. 1. Study of a Normal Man

During days 1 through 16 and days 19 through 24 he was depleted of sodium by cation exchange resin and a low sodium diet. During days 9 through 14 saline was given intravenously. Retention of enough sodium to produce a small expansion of extracellular fluid (ECF) volume as estimated from body weight led to a fall of urinary aldosterone to a very low level and to a greatly increased urinary excretion of sodium. During days 1 through 6 and days 19 through 24 the urinary sodium excretions were 0.6 and $0.7 \mathrm{mEq}$. per day.

Each subject ingested daily $355 \mathrm{mEq}$. (43 gm.) of a carboxylic cation exchange resin ${ }^{2}$ in the hydrogen and potassium form. The intake of resin began some days before the collection of data. Whenever intravenous saline was given, the quantity given each day was 2 liters containing

2 The preparation used was Natrinil, a pharmaceutical grade of Amberlite IRC-50 suitably prepared for therapeutic use.
253 millimols of sodium chloride and 55 millimols of sodium lactate. This was infused in a period of 2 hours or less. The excretion of 17-hydroxycorticoids, determined daily in several patients, was normal and did not vary during the studies.

\section{Normal subjects}

Two normal subjects were studied. The results of one study are shown in Figure 1. The results of the other study were essentially the same. Prior to the collection of data the subjects were depleted of sodium by resin and a low sodium diet. They were studied while depleted of sodium, then while receiving intravenous saline daily, and finally after being again depleted of sodium by resin and a low sodium diet. When each subject was depleted of sodium, his weight, urinary excretion of sodium, and sodium uptake by resin were lower and urinary excretion of aldosterone was higher than when body sodium was greater because of the daily intravenous infusion of saline. The average urinary excretion of aldosterone by each of the normal subjects during the days when intravenous saline was administered was $6 \mathrm{mi}$ crograms per day. Average serum sodium concentrations for the two subjects were slightly higher during the days that they received saline intravenously (Table I). During the days when saline was given intravenously, the uptake of potassium by resin was lower and the urinary potassium higher than during the days when the subjects were depleted of sodium. Serum potassium concentrations in both were slightly higher during the days that they received saline intravenously (Table I).

TABLE I

Serum electrolyte concentrations * during sodium depletion and repletion

\begin{tabular}{|c|c|c|c|c|c|}
\hline \multirow[b]{2}{*}{ Subject } & \multirow[b]{2}{*}{ Diagnoeis } & \multicolumn{2}{|c|}{ Serum sodlum } & \multicolumn{2}{|c|}{ Serum potassium } \\
\hline & & $\begin{array}{c}\text { Sodium } \\
\text { depleted }\end{array}$ & $\begin{array}{l}\text { Sodium } \\
\text { repleted }\end{array}$ & $\begin{array}{l}\text { Sodium } \\
\text { depleted }\end{array}$ & $\begin{array}{l}\text { Sodium } \\
\text { repleted }\end{array}$ \\
\hline $\begin{array}{l}\text { L. D. } \\
\text { W. Y. } \\
\text { F. H. } \\
\text { W. G. } \\
\text { J.L. } \\
\text { W. B. } \\
\text { F. R. } \\
\text { C. G. } \\
\text { V. B. }\end{array}$ & $\begin{array}{l}\text { Normal } \\
\text { Normal } \\
\text { Portal cirrhosis } \\
\text { Portal cirrhosis } \\
\text { Arteriosclerotic heart disease } \\
\text { Hypertensive heart disease } \\
\text { Hypertensive heart disease } \\
\text { Syphilitic aortic insufficiency } \\
\text { Arteriosclerotic heart disease }\end{array}$ & $\begin{array}{l}139 \\
139 \\
140 \\
140 \\
138 \\
138 \\
141 \\
127 \\
142\end{array}$ & $\begin{array}{l}141 \\
140 \\
144 \\
145 \\
144 \\
138 \\
142 \\
129 \\
128\end{array}$ & $\begin{array}{l}3.9 \\
4.4 \\
4.5 \\
3.0 \\
4.5 \\
5.5 \\
4.4 \\
6.5 \\
4.3\end{array}$ & $\begin{array}{l}4.1 \\
4.5 \\
4.2 \\
3.6 \\
4.6 \\
5.6 \\
5.0 \\
5.7 \\
5.6\end{array}$ \\
\hline
\end{tabular}
pletion.

* These values are the averages of the results of the determinations made during the periods of depletion and re- 


\section{Patients with cirrhosis}

Two patients with portal cirrhosis were studied. Results from one study are shown in Figure 2. Those of the other study were essentially the same. During the first part of the study neither patient had subcutaneous edema. One had slight ascites; the other had no ascites. Saline was then given intravenously daily until subcutaneous edema and marked ascites were present. The weight of each patient increased $7 \mathrm{Kg}$. The daily infusion of saline was then discontinued, and the edema and ascites allowed to persist for a number of days. For one of the patients there was an additional period of study following removal of the ascitic fluid by paracentesis.

When edema and ascites were present, urinary excretion of sodium and sodium uptake by resin were higher and urinary excretion of aldosterone was lower than when there was no edema and little or no ascites. The urinary excretion of sodium and the uptake of sodium by resin never reached as high levels and the urinary excretion of aldosterone never reached as low a level as the values for the normal subjects when intravenous saline was given. The average amounts of aldosterone excreted in the urine by the two patients when

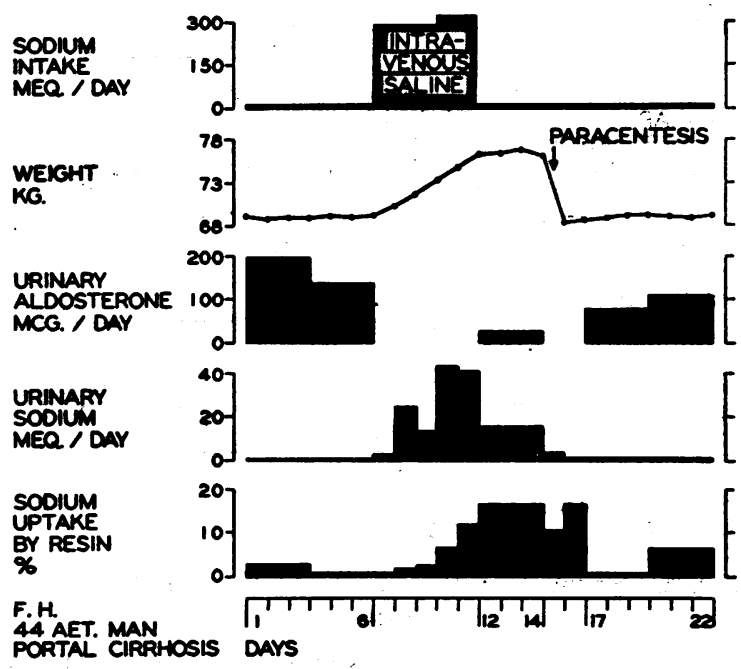

Fig. 2. Study of a Patrent with Portal Cirreosis

During days 1 through 6 and days 17 through 22 there were slight ascites and no edema. Edema and conspicuous ascites were produced by the intravenous administration of saline. Associated with retention of enough sodium to produce this expansion of ECF volume there was a decrease of urinary excretion of aldosterone and an increase in the excretion of sodium.

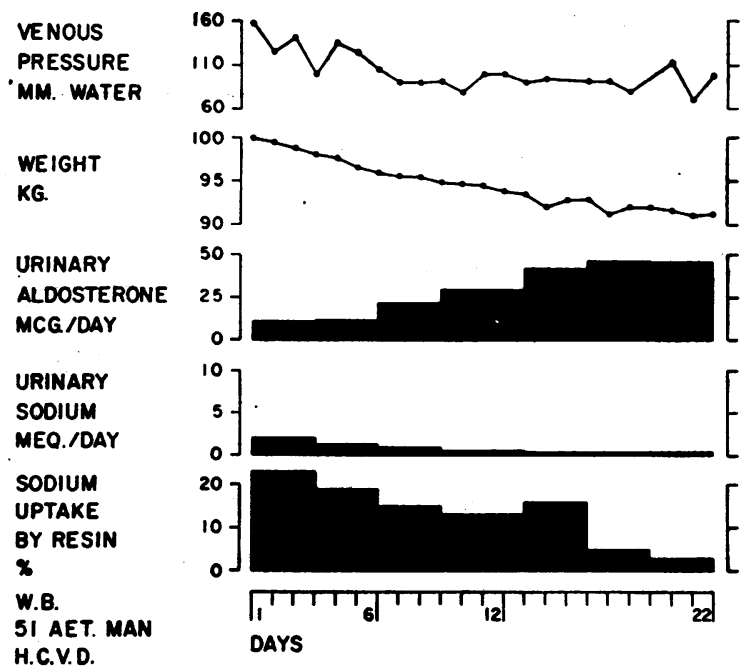

Fig. 3. Study of a Patient with Congestive Heart FAIIURE

The excretion of sodium on resin resulted in a gradual loss of edema which was not detectable after day 12 . The loss of sodium and edema was accompanied by a marked decrease in the excretion of sodium on resin, a gradual decrease in urinary sodium excretion, and 2 marked increase in excretion of aldosterone.

edema was present were 12 and 26 micrograms per day. When edema was present the average concentrations of sodium in the serum were somewhat higher than when edema was absent (Table I). When edema and conspicuous ascites were present, potassium uptake by resin was lower and urinary potassium higher than when there was no edema and little or no ascites. When edema was present the average concentration of potassium in the serum was slightly higher in one case and slightly lower in the other case than when no edema was present (Table I).

\section{Patients with congestive heart failure}

Five patients with heart failure were studied. The diagnoses for these patients are given in Table I. Results of the studies of 3 patients are illustrated in Figures 3 through 5. The data from the studies of the other two patients were essentially the same as those illustrated in Figures 3 and 4.

The responses of 4 of the patients to changes in body sodium were qualitatively similar to the responses of the normal subjects and the patients with cirrhosis. J. L. who had been maintained free of edema by sodium restriction and diuretic 


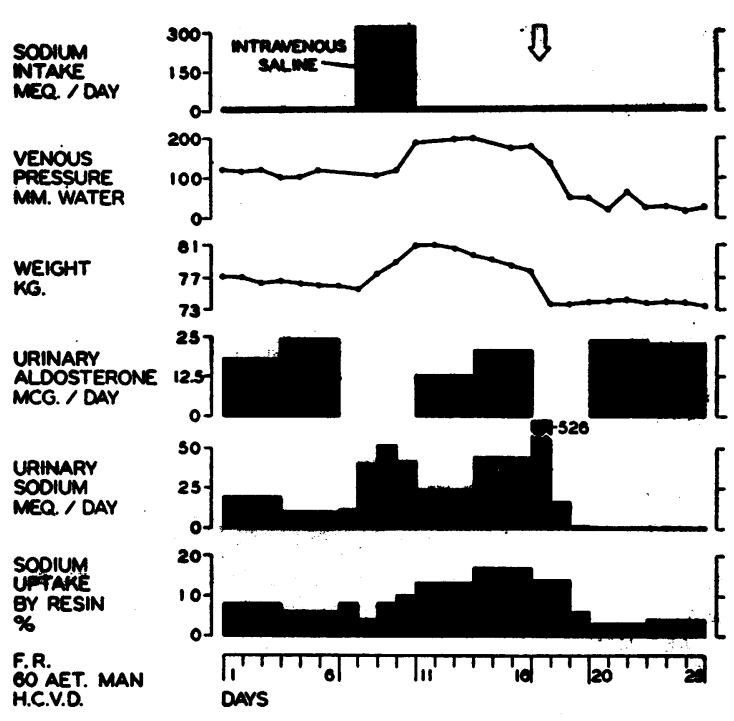

Fig. 4. Study of a Patient with Heart Failure

The figure illustrates the small change in aldosterone excretion which may result from retention of enough sodium to produce a relatively large expansion of ECF volume. There was no edema on days 1 through 6 and on days 20 through 25. Edema was present on days 11 through 16. The arrow indicates the injection of a mercurial diuretic.

therapy was made edematous by the intravenous infusion of saline. He was studied as he lost edema as a result of a moderate urinary excretion of sodium and the fecal excretion of sodium on resin. W. B. (Figure 3) was studied as he passed from an edematous to a non-edematous state as a result of a large fecal excretion of sodium. F. $\mathbf{R}$. (Figure 4) was studied while without edema, while edematous following the intravenous infusion of saline, and after loss of edema following use of a mercurial diuretic. C. G. was studied while only slight edema was present and after marked edema had been produced by intravenous saline. The changes in weight produced in these patients varied from 5 to $10 \mathrm{Kg}$.

When edema was present, urinary excretion of sodium and sodium uptake by resin were higher, and urinary excretion of aldosterone was lower than when edema was almost or completely absent. The urinary excretion of sodium and the uptake of sodium by resin never reached as high a level and the urinary excretion of aldosterone never reached as low a level as the values for the normal subjects during the days when saline was given intravenously. There was great variation in the responses of the patients with heart failure. In general, larger changes occurred in J. L. and W. B. than in F. R. and C. G. The average urinary aldosterone excretions of these patients while they were edematous were $13,14,17$ and $306 \mathrm{mi}-$ crograms per day. When edema was present the average serum sodium concentrations (Table I) were the same or slightly higher than when edema was absent. When edema was present, uptake of potassium by resin was lower and urinary potassium higher than when there was little or no edema. Serum potassium concentrations (Table I) were slightly higher in 3 cases when edema was present. It was somewhat lower in the fourth case. Venous pressure was much higher when edema was present.

The response (Figure 5) of the other patient (V. B.) with heart failure was opposite to that of the normal subjects. She had been in the hospital on a low sodium diet for a month prior to the study without evidence of change in cardiac function or in the gross edema that was present. During the first part of this study this gross edema

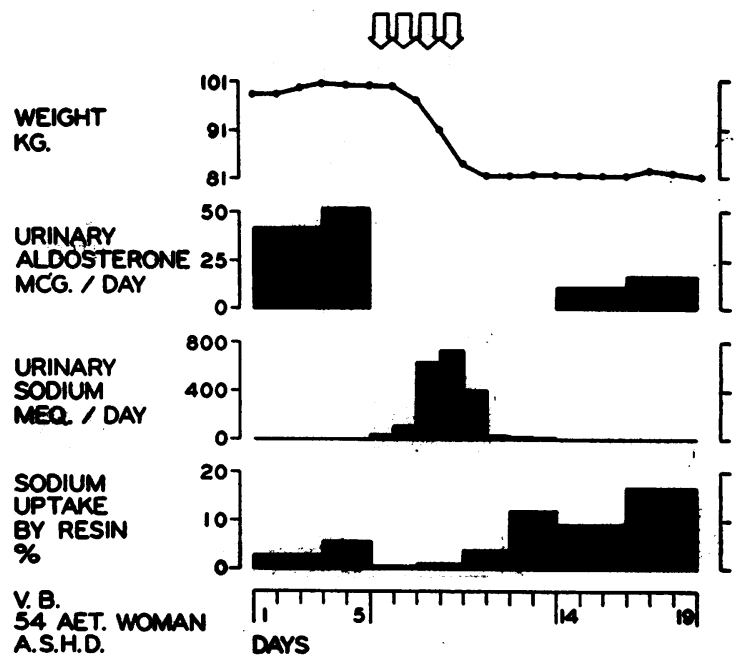

Fig. 5. Study of a Pateitt with Congestive Cardiac FAILURR

The great edema which was present in this.patient was removed by sodium depletion with injections of a mercurial diuretic as indicated by the arrows. This was followed by a decrease in urinary excretion of aldosterone and an increase in the uptake of sodium by resin. The average urinary excretion of sodium during the first 5 days was $1.5 \mathrm{mEq}$. per day and during the last 6 days $2.6 \mathrm{mEq}$, per day. The response in this case was qualitatively opposite to that usually seen. 
was allowed to persist. Then diuresis was produced by administration of a mercurial diuretic. She lost $20 \mathrm{Kg}$. Following this there was no subcutaneous edema. When edema was present, urinary excretion of sodium and uptake of sodium by resin were lower, and urinary excretion of aldosterone was higher than when there was no edema. Serum sodium concentration rose from 128 to 142 $\mathrm{mEq}$. per liter as edema was lost.

Urinary potassium and uptake of potassium by resin were approximately the same when there was edema as when there was none. Serum potassium fell from 5.6 to $4.3 \mathrm{mEq}$. per liter as edema was lost. Loss of edema was accompanied by a reduction of venous pressure from $250 \mathrm{~mm}$. to $150 \mathrm{~mm}$. of water.

\section{DISCUSSION}

Variation in the excretion of an adrenocortical steroid may be due to changes in the plasma concentration of the steroid or to changes in renal function (17). That the variation in the urinary aldosterone observed in the present study was due to changes in plasma aldosterone is indicated by two facts. First, sodium uptake by resin varied inversely with urinary aldosterone excretion. Since intestinal excretion of sodium is reduced by adrenocortical steroids $(18,19)$, a low uptake of sodium by resin, when urinary aldosterone is high, is evidence that a high level of circulating aldosterone is also present. Secondly, there was no variation in the renal excretion of 17-hydroxycorticoids as would have occurred if there had been changes in renal function of importance in the excretion of steroids. Thus in the following interpretation of the results of this study plasma aldosterone concentration is considered to have increased and decreased as urinary aldosterone excretion increased and decreased.

The responses of the two normal subjects to changes in body sodium were studied so that they could be compared with the responses of the patients with cirrhosis or heart failure. When body sodium was maintained at a high level the normal subjects weighed about $1 \mathrm{Kg}$. more than when they were depleted of sodium. This increment in weight is taken as a moderately accurate measure of the increase in ECF volume produced by the increase in body sodium. Immediately after the infusion of 2 liters of saline each day the ECF volume was expanded by another 2 liters. Thus the change in ECF volume was at no time much more than 3 liters. The increase in body sodium which produced this relatively small change in ECF volume resulted in a large increase in the urinary excretion of sodium. The increase in body sodium in some way also led to a decrease of circulating aldosterone to very low levels as estimated from urinary aldosterone.

It appears that in a normal individual an increase in body sodium such as to produce a relatively small increase in ECF volume reduces the circulating aldosterone to very low levels and that this is a factor in increasing the urinary excretion of sodium and thus preventing continued expansion of ECF volume. Factors which were not measured in the present study may also, of course, have been of importance in producing the changes in sodium excretion which occurred. Glomerular filtration, for example, may increase with sodium loading of normal men (20-23). Thus an increase in glomerular filtration may have contributed to the increased excretion of sodium by the normal subjects.

The present data do not bear on the question of how an increase in body sodium modifies the level of circulating aldosterone.

The responses of the patients with cirrhosis and of 4 of the 5 patients with heart failure to an increase in body sodium were qualitatively normal but quantitatively weak in that urinary excretion of sodium did not increase to as high a level nor circulating aldosterone, as estimated from urinary aldosterone, decrease to as low a level as in the normal subjects who had much smaller increases in body sodium and ECF volume.

The failure of patients with cirrhosis or heart disease to reduce aldosterone to very low levels following an increase in body sodium is probably an important factor in the further retention of sodium and formation of edema by these patients. The other factor of known importance is glomerular filtration rate (24). That neither of these factors is alone sufficient to cause sodium retention is demonstrated by two observations. First, the reduction of glomerular filtration which occurs in adrenal insufficiency does not lead to sodium retention nor indeed stop sodium loss. Secondly, patients with tumors which produce large 
amounts of aldosterone (25) do not retain much sodium.

It appears probable that one of the reasons that patients with cirrhosis do not respond quantitatively normally to an increase in body sodium and extracellular fluid volume is that most of the sodium and fluid is in the abdomen. The rest of the body may still have a low sodium and extracellular fluid content. The results of this study do not suggest any explanation of why patients with heart failure have a quantitatively weak response to retention of sodium and water.

The change in sodium excretion and aldosterone produced by retention of sodium in one patient was exactly opposite to the change produced in the other patients and normal subjects. That this is an unusual response is shown by its occurrence in only one of the patients in this study and in none of the patients in previous studies $(14,26)$ in whom the degree of edema was varied by sodium administration or deprivation, and sodium excretion in urine and onto resin determined. The occurrence of this unusual response indicates that some factor which did not play a decisive role in the other patients was decisive in this patient. One possibility is that this factor was the myocardial response to alteration in venous pressure. Reduction of the venous pressure of patients with heart failure may lead to improvement in cardiac function as measured by cardiac output (27). In this patient, retention of sodium and expansion of ECF volume may have increased venous pressure enough to impair myocardial function and thus have led to an increase in circulating aldosterone.

When the response of a patient with edema to further retention of sodium is qualitatively normal but weak, the accumulation of edema becomes progressively slower because of the increased sodium excretion that occurs as edema increases. However, despite a degree of edema that caused severe symptoms, the patients observed in this study could have maintained a steady state as far as ECF volume was concerned only if their dietary sodium were low. A patient who responds to an increase in body sodium with an increase in aldosterone is in a peculiarly unfavorable position. As edema accumulates he becomes even more prone to accumulate additional edema.

Potassium excretion on resin by patients and normal subjects was greater when body sodium and thus ECF volume were relatively low than when they were large. This may have been due in part to a direct effect of aldosterone on the intestinal excretion of potassium. However, it may have been due only to the presence of less sodium on resin when body sodium was low since a decrease in sodium on resin leaves more exchange capacity available for potassium.

The increased fecal excretion of potassium when body sodium was relatively low resulted in decreased net intestinal absorption of potassium. This led to decreased urinary excretion of potassium. This decrease in urinary potassium excretion was not due to a change in circulating aldosterone. It occurred despite an increase in circulating aldosterone which tends to increase potassium excretion (7).

\section{SUMMARY}

The urinary excretion of aldosterone and sodium and the fecal excretion of sodium onto cation exchange resin have been studied in normal men and in patients with heart failure or portal cirrhosis in whom the body content of sodium has been experimentally varied. Reasons are advanced for considering urinary aldosterone excretion a measure of circulating aldosterone.

A relatively small increase in the body sodium of normal men decreases the urinary excretion of aldosterone greatly. The decrease in circulating aldosterone which this reflects is probably an important factor in the increased urinary excretion of sodium which occurs at the same time. This response tends to prevent a continued increase in body sodium and thus extracellular fluid (ECF) volume.

Retention of enough sodium to produce marked expansion of the ECF volume of patients with heart failure or portal cirrhosis usually produces changes in aldosterone and sodium excretion qualitatively similar to those occurring in normal subjects with relatively small increases in body sodium and ECF volume. However, aldosterone excretion does not fall to as low a level nor sodium excretion rise as high as in normal subjects.

The failure of aldosterone to fall to very low levels in response to an increase in body sodium is probably an important factor in the formation 
of edema in patients with heart failure or portal cirrhosis.

\section{Addendum}

Since the completion of this study, an abstract has been published stating that increasing dietary sodium decreases but does not return to normal the urinary excretion of aldosterone by patients with heart failure. (E. S. Gordon, J. Lab. \& Clin. Med., 1955, 46, 820.)

\section{ACKNOWLEDGMENT}

The dietetic aid of Miss Merme Bonnell is very gratefully acknowledged.

\section{REFERENCES}

1. Tait, J. F., Simpson, S. A., and Grundy, H. M., The effect of adrenal extract on mineral metabolism. Lancet, 1952, 262, 122.

2. Simpson, S. A., Tait, J. F., Wettstein, A., Neher, R., v. Euw, J., and Reichstein, T., Isolierung eines neuen kristallisierten Hormons aus Nebennieren mit besonders hoher Wirksamkeit auf den Mineralstoff wechsel. Experientia, 1953, 9, 333.

3. Simpson, S. A., Tait, J. F., Wettstein, A., Neher, R., v. Euw, J., Schindler, O., and Reichstein, T., Konstitution des Aldosterons, des neuen Mineralocorticoids. Experientia, 1954, 10, 132.

4. Simpson, S. A., Tait, J. F., and Bush, I. E., Secretion of a salt-retaining hormone by the mammalian adrenal cortex. Lancet, 1952, 263, 226.

5. Luetscher, J. A., Jr., and Johnson, B. B., The sodiumretaining corticoid of human urine: its nature and some physiological factors governing its secretion. J. Clin. Invest., 1953, 32, 585.

6. Luetscher, J. A., Jr., and Axelrod, B. J., Increased aldosterone output during sodium deprivation in normal men. Proc. Soc. Exper. Biol. \& Med., 1954, 87, 650.

7. Gaunt, R., Renzi, A. A., and Chart, J. J., Aldosterone $\neg$ a review. J. Clin. Endocrinol. \& Metab., 1955, 15, 621.

8. Deming, Q. B., and Luetscher, J. A., Jr., Bioassay of desoxycorticosterone-like material in urine. Proc. Soc. Exper. Biol. \& Med., 1950, 73, 171.

9. Luetscher, J. A., Jr., and Johnson, B. B., Observations on the sodium-retaining corticoid (aldosterone) in the urine of children and adults in relation to sodium balance and edema. J. Clin. Invest., 1954, 33, 1441.

10. Luetscher, J. A., Jr., Neher, R., and Wettstein, A., Isolation of crystalline aldosterone from the urine of a nephrotic patient. Experientia, 1954, 10, 456.

11. Singer, B., and Wener, J., Excretion of sodium-retaining substances in patients with congestive heart failure. Am. Heart J., 1953, 45, 795.
12. Chart, J. J., and Shipley, E. S., The mechanism of sodium retention in cirrhosis of the liver. J. Clin. Invest., 1953, 32, 560.

13. Pechet, M. M., Duncan, L. E., Jr., Liddle, G. W., and Bartter, F. C., Studies on a salt retaining factor prepared from human urine. J. Clin. Invest., 1954, 33, 957.

14. Duncan, L. E., Jr., Treatment of edema by removal of body sodium by a cation exchange resin. Am. J. Med., 1953, 14, 425.

15. Liddle, G. W., Cornfield, J., Casper, A. G. T., and Bartter, F. C., The physiological basis for a method of assaying aldosterone in extracts of human urine. J. Clin. Invest., 1955, 34, 1410.

16. Silber, R. H., and Porter, C. C., The determination of 17, 21-dihydroxy-20-ketosteroids in urine and plasma. J. Biol. Chem., 1954, 210, 923.

17. Marks, L. J., and Leaf, A., The relationship of the renal excretion of adrenal corticoids to variations in renal hemodynamics. J. Clin. Invest., 1953, 32, 813.

18. Dennis, C., and Wood, E. H., Intestinal absorption in the adrenalectomized dog. Am. J. Physiol., 1940, 129, 182.

19. Berger, E. Y., Quinn, G. P., and Homer, M. A., Effect of desoxycorticosterone on the colon: Its relation to the action of cation exchange resins in man. Proc. Soc. Exper. Biol. \& Med., 1951, 76, 601.

20. Leaf, A., Couter, W. T., and Newburgh, L. H., Some effects of variation in sodium intake and of different sodium salts in normal subjects. J. Clin. Invest., 1949, 28, 1082.

21. Green, D. M., Bridges, W. C., Johnson, A. D., Lehman, J. H., Gray, F., and Field, L., Relation of glomerular filtration rate and sodium tubular rejection fraction to renal sodium excretion. Am. J. Physiol., 1950, 160, 306.

22. Crawford, B., and Ludemann, H., The renal response to intravenous injection of sodium chloride solutions in man. J. Clin. Invest., 1951, 30, 1456.

23. Despopoulos, A., and Fitzmorris, A. O., Renal adjustments to large saline loads in the normal and in diabetes insipidus. J. Clin. Endocrinol., 1952, 12, 955.

24. Merrill, A. J., and Cargill, W. H., The effect of exercise on the renal plasma flow and filtration rate of normal and cardiac subjects. J. Clin. Invest., 1948, 27, 272.

25. Conn, J. W., Primary aldosteronism, a new clinical syndrome. J. Lab. \& Clin. Med., 1955, 45, 3.

26. Duncan, L. E., Jr., Effect of edema and dietary sodium on efficacy of sodium removal by cation exchange resin. Am. Heart J., 1953, 45, 802.

27. Howarth, S., McMichael, J., and Sharpey-Schafer, E. P., Effects of venesection in low output heart failure. Clin. Sc., 1946, 6, 41. 